\title{
Henoch Schonlein Purpura in children: clinical analysis of 120 cases
}

\author{
Chen $\mathrm{O}^{1,2}$, Zhu XB ${ }^{1}$, Ren $\mathrm{P}^{5}$, Wang $\mathrm{YB}^{3}$, Sun $\mathrm{RP}^{1}$, Wei $\mathrm{DE}^{4}$
}

1. Department of Pediatrics, Qilu Hospital, Shandong University, \#107 West Wenhua Road, Jinan 250012,China.

2. Dvision of nursing management, Nursing School, Shandong University, \#44 West Wenhua Road, Jinan 250012, China.

3.Department of Pediatrics, Second Hospital, Shandong University, \#247 Beiyuan Road, Jinan 250033, China. 4.Department of Gynecology, Jinan Center Hospital, \#105 Jiefang Road, Jinan 250013, China.

5.Department of Orthopedics, Second Hospital, Shandong University, \#247 Beiyuan Road, Jinan 250033, China.

\begin{abstract}
Background: Henoch Schonlein Purpura (HSP) is a systemic vasculitic disease which is common in children. It is very important to understand the clinical features of this disease for doctors and nurses.

Objectives: To study the clinical characteristics of HSP in children.

Methods: Collect the clinical data of the HSP children, and analyze the clinical characteristics of these HSP patients.

Results: The ratio of M:F was 1.9:1. The mean age was $6.6 \pm 1.6$ years. The typical onset seasons were spring, winter and autumn. Infection and food allergy were the main etiological factors. The first symptom was skin purpura and these purpura mainly concentrated the lower extremities and buttocks. The dominant digestive clinical features were abdominal pains and vomiting. The knee joint and ankle joint were most frequently affected. The typical kidney symptoms were microscopic hematuria and albuminuria. An increased ESR was reported in 68 patients (56.7\%). Serum C3 decreased in 13 cases $(10.8 \%)$. ASO titer was higher in 57 children (47.5\%).

Conclusion: There were gender, season and area differences for the HSP patients. The etiological factors were diverse. HSP patients could have various clinical symptoms and rare complications.

Key words: Henoch Schonlein Purpura, Children

African Health Sciences 2013; 13(1): 94 - 99 http://dx.doi.org/10.4314/ahs.v13i1.26
\end{abstract}

\section{Introduction}

Henoch Schonlein Purpura(HSP), was first recognized in 1801 by Heberden and first described as an association arthritis by Schonlein in $1837 . .^{1}$ It is a systematic vasculitic disease, and mainly affects the small vessels of skin, joints, gastrointestinal tract, and kidneys. In some series, boys are affected more than girls. ${ }^{2}$ The mean age of HSP patients is 6 years; $75 \%$ of the patients are under 8 years of age and $90 \%$ are less than 10 years of age. ${ }^{3-5}$ Although many antigens, such as foods, infective agents, drugs, vaccinations, and insect bites have been reported to be related to HSP, the etiology of this disease remains unclear. ${ }^{6-8}$ The pathogenesis also remains unknown. At present, HSP is regarded as an inflammation and immune-mediated disease. ${ }^{9} \operatorname{IgA}$ and some proinflammatory cytokines have the pivotal role in

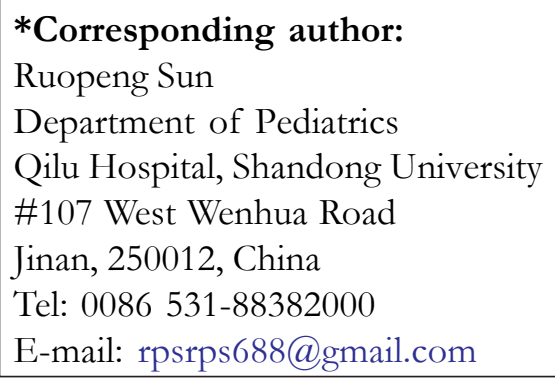

the pathogenesis of HSP. ${ }^{10}$

The typical clinical characteristics involve the triad of palpable purpura, abdominal pain and arthritis. Progressive renal function impairment, bowel perforation, central nerve system involvement are rare. The occurrence of purpura, which are nonthrombocytopenic, is the essential element for the diagnosis of HSP. The purpura are often located on some parts just as lower extremities and buttocks. ${ }^{10} \mathrm{HSP}$, in general, is considered benign and self-limited and the treatment is supportive.

The aim of our study is to analyze the clinical data of the HSP children, and discuss the clinical characteristics of HSP in children. We think knowing about the clinical features could help doctors to make the correct diagnosis and provide the correct remedy and nursing.

\section{Methods}

This is a retrospective study. The patients were HSP children treated from the Qilu Hospital, between 2007 and 2010. We selected the patients who accepted the whole remedy in the pediatric bed-ward of Qilu Hospital. Those patients who left the hospital 
before improvement and recovery were excluded form our study. The diagnosis criteria were the American College of Rheumatology 1990 criteria for the classification of $\mathrm{HSP}^{11}$. Approval for this research was obtained from the Medical Ethic Committee of the Qilu Hospital.

\section{Definition}

The epidemiological data were analyzed: City means the settlements where the non-agricultural industries and non-agricultural population concentrate in. Countryside means the area where the agricultural production laborers inhabited in. Spring includes March, April and May. Summer means June, July and August. Autumn refers to September, October and November. Winter means December, January and February. Previous infection, special food, vaccination, insect bite, and accident were considered as the precipitating factors to be specially retrospectively looked, if they happened in 2 weeks before HSP onset. Preceding infection was self reported.

About the clinical characteristics, we defined as follows: Microscopic hematuria wasdefined when the test result was $>+$; Albuminuria was defined when the test result was $>+$; Gross hematuria was defined blood in the urine could be seen with the naked eye; Tubular urine was defined one more urinary cylinder were found per low power field. Rash location means purpura mainly concentrated in the parts of the body.
The laboratory data were defined: Elevated ESR was defined when ESR was $>20 \mathrm{~mm} / 1$ hour; increased ASO titer when $>300 \mathrm{IU} / \mathrm{mm}$; low C3 when $<900 \mathrm{mg} / \mathrm{L}$.

\section{Statistical analysis}

All data were described as means and standard deviations (mean $\pm \mathrm{SD}$ ) or medians and ranges. Categorical variables were expressed by percentages.

\section{Results \\ Epidemiological features}

The main epidemiological data are shown in table 1. There were 120 children fulfilling the diagnosis criteria between January 2007 to December 2010. The 120 HSP children included $78(65 \%)$ boys and $42(35 \%)$ girls. Males were affected more than the females (Ratio M:F=1.9:1). The age range was from 1 to 12 years ( mean age $6.6 \pm 1.6$ years). The age and gender distribution showed that most HSP children ( 103 cases, $85.3 \%$ ) were less than 8 years old, $88.3 \%$ were $<10$ years old, and 98 cases of HSP children (81.7\%) were between 5 and 8 years old (figure 1). It was found that 40 cases $(33.3 \%)$ occurred in spring, 12 cases $(10 \%)$ in summer, 24 cases $(20 \%)$ in autumn, and 44 cases $(36.7 \%)$ in winter. The countryside patients were 73 cases $(60.8 \%)$, while there were 47 city children $(39.2 \%)$. For 98 cases, this was their primary presentation. There were 22 relapse patients.

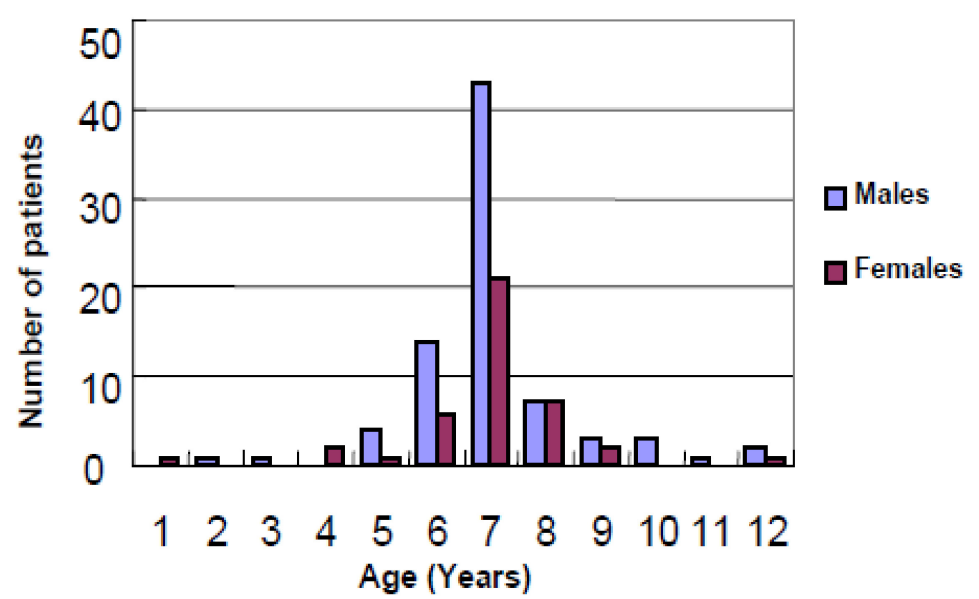

Figure 1: Age and gender distribution of $120 \mathrm{HSP}$ patients 
The age range was from 1 to 12 years (mean age 6.6 \pm 1.6 years). The age and gender distribution showed that most HSP children (98cases, 81.7\%) were less than 8 years old, and 103 cases of the HSP children $(85.3 \%)$ were part of the age range between 5 and 8 years old (figure 1).

Before HSP onset, there were 73 cases $(60.8 \%)$ who had an infection, and among these patients, 52 children had an upper respiratory tract infection; 17 cases had bronchial pneumonia; 4 patients had enteritis. The results revealed 32 patients had eaten special food just as fish or shrimp before onset, and there were 2 children who had been given a measles-mumps-rubella vaccination 2 weeks before HSP onset, and 1 child who had been accepted a Hepatitis B vaccine 1 weeks before HSP coming. Parasite infection was reported in 3 patients $(2.5 \%)$, and among these children, ascarids attacked 1 child, and the other two had been infected by threadworms. Tick bites were announced in 2 cases one week before disease onset. Two children had choked with water seriously during swimming before. There were unknown etiological factors in four children before disease onset.

Table 1: Epidemiological data in 120 children with HSP

\begin{tabular}{|c|c|c|}
\hline & $\begin{array}{l}\text { Children } \\
(n=120)\end{array}$ & $\begin{array}{l}\text { Percentage } \\
(\%)\end{array}$ \\
\hline \multicolumn{3}{|l|}{ Age(years) } \\
\hline Mean \pm SD & $6.6 \pm 1.6$ & \\
\hline Range & $1-12$ & \\
\hline Sex: Male/Female & $78 / 42$ & \\
\hline Proportion of boys & & 65 \\
\hline Ratio M:F & 1.9:1 & \\
\hline \multicolumn{3}{|c|}{ Possible etiological factors } \\
\hline Infection & 73 & 60.8 \\
\hline Food allergy & 32 & 26.7 \\
\hline Vaccination & 3 & 2.5 \\
\hline Parasite infection & 4 & 3.3 \\
\hline Tick bite & 2 & 1.6 \\
\hline Emergencies & 2 & 1.6 \\
\hline Unknown & 4 & 3.3 \\
\hline \multicolumn{3}{|l|}{ Seasonal pattern } \\
\hline Spring & 40 & 33.3 \\
\hline Summer & 12 & 10.0 \\
\hline Autumn & 24 & 20.0 \\
\hline Winter & 44 & 36.7 \\
\hline \multicolumn{3}{|l|}{ Area distribution } \\
\hline Countryside & 73 & 60.8 \\
\hline City & 47 & 39.2 \\
\hline \multicolumn{3}{|c|}{ Situation of disease onset } \\
\hline First & 98 & 81.7 \\
\hline Recurrence & 22 & 18.3 \\
\hline
\end{tabular}

City means the settlements where the non-agricultural industries and non-agricultural population concentrate in. Countryside means the area where the agricultural production laborers inhabited in period. Spring are March, April and May. Summer are June, July and August. Autumn are September, October and November.. Winter are December, January and February.

Table 2: Main clinical features of the 120 children with HSP

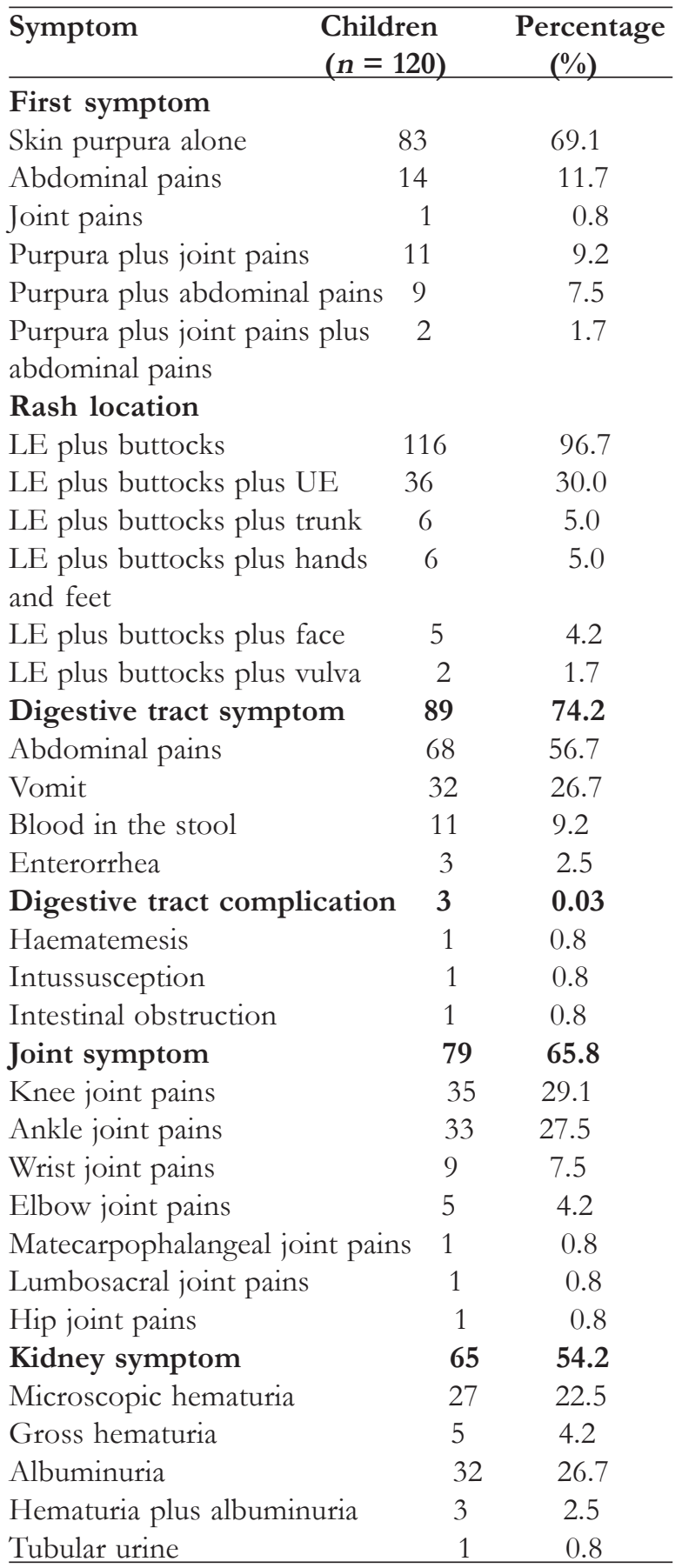


Continuation of table 2

\begin{tabular}{lcc}
\hline Symptom & $\begin{array}{c}\text { Children } \\
(\boldsymbol{n}=\mathbf{1 2 0})\end{array}$ & $\begin{array}{c}\text { Percentage } \\
(\mathbf{\%})\end{array}$ \\
\hline Other symptom & & 4.2 \\
Calf swelling & 5 & \\
Miscellanous & 2 & 1.7 \\
Orchitis & 3 & 2.5 \\
Pneumonia &
\end{tabular}

Abbreviations: LE, lower extremities; UE, upper extremities.

Microscopic hematuria was defined when the test result was $>+$; Albuminuria was defined when the test result was $>+$; Gross hematuria was defined blood in the urine could be seen with the naked eye; Tubular urine was defined one more urinary cylinder were found per low power field period.

\section{Table 3: Laboratory findings in 120 children of HSP}

\begin{tabular}{lcc}
\hline Findings & $\begin{array}{c}\text { No. Positive/ } \\
\text { No. Tested }\end{array}$ & $\begin{array}{c}\text { Percentage } \\
\mathbf{( \% )}\end{array}$ \\
\hline Elevated ESR & $68 / 120$ & 56.7 \\
Increased ASO titer & $57 / 120$ & 47.5 \\
Low $C_{3}$ serum levels & $13 / 120$ & 10.8 \\
\hline
\end{tabular}

Elevated ESR was defined when ESR was $>20 \mathrm{~mm} /$ 1 hour; increased ASO titer when $>300 \mathrm{IU} / \mathrm{mm}$; low $\mathrm{C}_{3}$ when $<900 \mathrm{mg} / \mathrm{L}$.

\section{Clinical features}

The main clinical characteristics of the 120 HSP children were showed in table 2 .

\section{First symptom}

The first symptoms were diverse. It was found that 83 cases $(69.1 \%)$ displayed skin purpura alone, while 14 patients $(11.7 \%)$ told abdominal pains. One child $(0.8 \%)$ had joint pains, and purpura and joint pains were reported in 11 children ( $9.2 \%)$. We also found nine patients $(7.5 \%)$ had purpura and abdominal pains meanwhile, and the joint pains, purpura and abdominal pains were complainted in 2 cases.

\section{Purpura}

All children appeared skin eruption. The purpura lesions of most patients were concentrated on the lower extremities and buttocks.

\section{Digestive tract manifestation}

Among these children, abdominal pains occurred in 68 cases $(56.7 \%)$. The results showed 32 patients
(26.7\%) nausea, 11 children ( $9.2 \%)$ had blood in the stool, and 3 cases (2.5\%) occured enterorrhea. Serious manifestations were gastrointestinal complications: 1 child $(0.8 \%)$ haematemesis, 1 case $(0.8 \%)$ intussusception, and 1 patient $(0.8 \%)$ intestinal obstruction.

\section{Joint symptom}

Joint involvement occurred in many HSP children. These patients complained joint swelling. The results about the affected joints showed knee joints in 35 cases (29.1\%), ankle joints in 33 children (27.5\%), wrist joints in 9 patients $(7.5 \%)$, elbow joints in 5 children (4.2\%), metacarpophalangeal joints in 1 child $(0.8 \%)$, lumbosacral joints in 1 child $(0.8 \%)$, and hip joints in 1 child $(0.8 \%)$.

\section{Kidney symptom}

Microscopic hematuria occurred in 27 children $(22.5 \%)$, and gross hematuria were found in 5 cases $(4.2 \%)$. Albuminuria were reported in 32 patients $(26.7 \%)$, and there were three cases $(2.5 \%)$ who appeared hematuria except albuminuria. We also found one tubular urine child $(0.8 \%)$.

\section{Uncommon clinical features}

The results showed calf swelling in 5 cases (4.2\%), orchitis in 2 children (1.7\%). We also found 3 HSP cases had pneumonia during they accepted the remedy.

\section{Laboratory findings}

The main laboratory data of the acute phase were showed in Table 3. An increased ESR was reported in 68 patients $(56.7 \%)$. Serum C3 decreased in 13 cases $(10.8 \%)$. ASO titer was higher in 57 children $(47.5 \%)$.

\section{Treatment}

The main resolved drug included the glucocorticoid, immunosuppressor, antihistamine drug, calcium channel blocker drug.

\section{Outcome}

There were 89 patients $(74.2 \%)$ had been cured, and the conditions of 31 children of HSP $(25.8 \%)$ improved. 


\section{Discussion}

HSP which is characterized by a purpuric rash, arthritis, nephritis and gastrointestinal symptoms is a systemic vasculitis of unknown etiology. ${ }^{9}$ It is the most common childhood vaculitis, with an annual incidence of about 10 cases per 100,000. ${ }^{2}$ HSP was announced in association with infections, medications, vaccination. The pathogenesis is poorly understood. It was reported an IgA-mediate disease. ${ }^{10}$ This multisystem disease mainly affected skin, kidneys, joints, gastrointestinal tract, and other organs still could be affected. It is considered nonfatal and self-limiting. Renal involvement could make the chronic consequences of HSP patients. ${ }^{2}$

The HSP children are mainly between the ages of 5 and 15 years and the mean age is 5 to 6 years. ${ }^{3,4,6,7,12-15}$ In our investigation, the patients ranged from 1 to 12 years. According to our study, HSP occurs most frequently between the age of 6 to 7 years old, $88.3 \%$ were $<10$ years old, only 3 cases were $<2$ years old, and the mean age was $6.6 \pm 1.6$ years. In our literature, $65 \%$ of the patients were boys and 35\% were girls. The ratio of M:F was 1.9:1. According to the findings, the boys are affected more often than the girls, and this findings were in accord with Frank T Saulsbury's "Clinical update: HenochSchonlein Purpura". ${ }^{2}$ Gender distinction about the HSP incidence was also reported in other studies. In these investigations, HSP in children was more common in males. ${ }^{3,14,16} \mathrm{By}$ contrast, female advantage was found in these studies. ${ }^{4,17}$

According to our results, the incident seasons were spring, winter and autumn. The lowest incidence was in summer. The research outcomes were similar with some reports., $3,42-15,17-21$ The etiological factors are still unclear. Our reports showed that 73 patients $(60.8 \%)$ experienced infection before HSP onset and 32 cases (26.7\%) occurred food allergy. Infection and food allergy were the main etiological factors in our study. Children often experienced respiratory tract infections in the cold months, so the high incidence in cold months suggested the association between HSP with infection, and this conclusion was alike with some investigations. ${ }^{3,14,22}$ Some accounts had reported the trigger events including vaccinations, insect bites, and drugs have been connected with HSP. ${ }^{23,24}$ In the present investigation, infection, food allergy, vaccination, parasite infection, insect bite, and emergency all may be potential trigger events for HSP onset. Furthermore we could not find the relevant factors about HSP onset for some patients.

In this study, we found that the incidence of the countryside children had been higher than the patients from the city. One of the reasons leading to this result may be the different hygiene and environment between city and countryside.

In terms of our research, the first symptoms for the HSP children were different. A majority of the HSP patients displayed skin purpura alone at the onset. The purpura lesion concentrated the lower extremities and buttocks. The skin eruption of all patients faded during 2 to 40 days, and the averages were $9.14 \pm 5.42$ days.

We discovered many HSP children displayed the digestive system symptoms. The dominant digestive clinical features were abdominal pains and vomiting. Digestive complications just as haematemesis, intussusception and intestinal obstruction could also occur. Gastrointestinal involvement buffered during 1 to 30 days, and the averages were $4.15 \pm 1.14$ days.

Many HSP patients displayed the joint symptom. The knee joint and ankle joint were most frequently affected, and the results were same with Sandra and coworkers. ${ }^{5}$ In our study, the other joints just as wrist joint, elbow joint, metacarpophalangeal joint and hip joint were reported to be affected.

In our report, the typical kidney symptoms were microscopic hematuria and albuminuria. We also detected some cases occurred uncommon clinical features, just as calf swelling, orchitis and pneumonia.

\section{Conclusion}

We considered that there were gender difference, season difference and area difference for HSP children. The etiological factors were diverse. HSP patients could have various clinical symptoms and rare complications. Knowing well the diversiform clinical features of the HSP could help us to make the correct diagnosis and give the right cure and nursing. Although the epidemiology, clinical characterics, treatments, prognosis of HSP have been researched for many years, several questions still remain. Why do some children have the serious complication? Why do some children progress to end-stage renal disease? So we thought the investigation about the genetic susceptibility to HSP, immune pathogenesis, and more effective treatment still had been needed in this area. 


\section{Acknowledgements}

This work was supported by National Natural Science Foundation of China (grants 81070396, 81100334), the development of science and technology plan projects of Shandong Province (grant 2010GSF10234), the Natural Science Foundation of Shandong Province (grants ZR2011HM078, ZR2010HQ002), the Medicine and health development plan of Shandong Province (grant 2011QW012).

\section{References}

1. Tarvin SE, Ballinger S. Henoch Schonlein Purpura. Current Paediatrics. 2006;16(4):259-263.

2. Saulsbury FT. Clinical update: Henoch Schonlein Purpura. Lancet. 2007; 369(9566): 976-978.

3. Saulsbury FT. Henoch Schonlein Purpura in children: report of 100 patients and review of the literature. Medicine. 1999;78(6):395-409.

4. Calvino MC, Llorca J, Garcia-Porrua C, Fernandez-lqlesias JL, Rodriquez-Ledo P, Gonzalez-Gay MA. Henoch Schonlein Purpura in children from northwestern Spain: a 20-year epidemiologic and clinical study. Medicine. 2001;80(5):279-290.

5. Trapani S, Micheli A, Grisolia F, et al. Henoch Schonlein Purpura in childhood: epidemiological and clinical analysis of 150 cases over a 5 -year period and review of literature. Semin Arthritis Rheum. 2005;35(3):143-153.

6. Cassidy JT, Petty RE. Leukocytoclastic vasculitis. New York : Churchill Livingstone, 2001.

7. Dillon MJ. Childhood vasculitis. Lupus. 1998;7(4):259-265.

8. Lahita RG. Influence of age on Henoch Schonlein purpura. Lancet. 1977; 350(9085):11161117.

9. Gow KW, Murphy JJ 3rd, Blair GK, Magee JF, Hailey J. Multiple Entero-Entero Fistulae: An Unusual Complication of Henoch-Schonlein Purpura. J Pediatr Surg. 1996;31(6):809-811.

10. Yang YH, Chuang YH, Wang LC, Huang HY, Gershwin ME, Chiang BL The immunobiology of Henoch-Schonlein purpura, Autoimmun Rev. 2008:7(3):179-184.

11. Mills JA, Michel BA, Bloch DA, et al. The American College of Rheumatology 1990 criteria for the classification of Henoch Schonlein purpura. Arthritis Rheum. 1990;33(8):1114-1121.

12. Sano H, Izumida M, Shimizu H, Oqawa Y. Risk factors of renal involvement and significant proteinuria in Henoch Schonlein Purpura. EurJ Pediatr. 2002;161(4):193-201.

13. Stewart M, Savage JM, Bell B, McCord B. Long term renal prognosis of Henoch Schonlein Purpura in unselected childhood population. Eru J Pediatr. 1988;147(2):113-115.

14. Abdel-Al Y-K, Hejazi Z, Majeed HA. Henoch Schonlein Purpura in Arab children. Analysis of 52 cases. Trop Georg Med. 1990; 42(1):52-57.

15. Gardner-Medwin JMM, Dolezalova P, Commins C, Southwood TR. Incidence of Henoch Schonlein Purpura, Kawasaki disease and rare vasculitides in children of different ethnic origins. Lancet. 2002;360(9341):1197-1202.

16. Blanco R, Martinez-Taboada VM, Rodriguez Valverde V, Garcia-Fuentes M. Cutaneous Vasculitis in children and adults: associated diseases and etiologic factors in 303 patients. Medicine. 1998;77(6):403-418.

17. Garcia-Porrua C, Calvino MC, Llorca J, Couselo JM, Gonzalez-Gay MA. Hench Schonlein Purpura in children and adults: clinical differences in a defined population. Semin Arthritis Rheum. 2002;32(3):149-156.

18. Garcia-Porrua C, Gonzalez-Gay MA. Comparative clinical and epidemiological study of hypertensitivity vasculitis versus Henoch Schonlein purpura in adults. Semin Arthritis Rheum. 1999;28(6):404-412.

19. Farley TA, Gillespie S, Rasoulpour M, Tolentino N, Hadler JL, Hurwitz E. Epidemiology of a cluster of Henoch Schonlein purpura. Am J Dis Child. 1998;143(7):789-803.

20. Nielsen HE. Eepidemiology of SchonleinHenoch purpura. Acta Pediatr Scand. 1988;77(1):125-131.

21. Dolezalova P, Telekesova P, Nemkova D, Hoza $\mathrm{J}$. Incidence of vasculitis in children in the Czech republic:2-year prospective epidemiology survey. J Rheumatol. 2004;31(11):2295-2299.

22. Rasmussen NH. Henoch-Schonlein purpura after Yesinia. Arch Dis Child. 1992;57(4):322-327.

23. Patel U, Bradley JR, Hamilton DV. Henoch Schonlein purpura after influenza vaccination. $\mathrm{Br}$ Med J. 1988;296(6639):1800.

24. Courtney PA, Patterson RN, Lee RJ. Henoch Schonlein purpura following meningitis C vaccination. Rheumatology. 2001;40(3):345-346. 